\title{
Skin Anti-Aging Benefits of Phytotherapeutics-based Emulsions
}

\section{Farid Menaa*}

Bionanomics Ltda, Sao Paulo, Fluorotronics, California, USA

The modern medicine still needs the help of the alternative and complementary medicine, which is most often based on phytotherapy. Therefore, the identification and characterization of plant extracts and their major bioactive phytochemicals (e.g. polyphenols, triterpenes, carotenoids, vitamins) are highly valuable, especially if they, as natural compounds encapsulated or not, are proved to be more efficient and less toxic compared to that of conventional chemical formulations (i.e. synthetic or semi-synthetic compounds) used as drugs to prevent or treat diseases (e.g. melasma, melanoma, acne, dermatitis, skin sunburns), nutraceutics/food supplements (e.g. antioxidants, antiinfllammatory compounds) or cosmeceutics for topical application to delay physiological or pathological/premature aging (e.g. skin aging) [1-7].

Recent advances in biotechnology have demonstrated the feasibility of encapsulating plant extracts or derived-pure phytochemicals into various types of carriers (e.g. emulsions aka colloids or polymers in dispersed systems, other biocompatible and biodegradable polymers) in order to more specifically target the damaged tissue while enhancing their systemic bioavailability and reducing their cytotoxicity $[3,4,8,9]$. In this context, the administration route represents an important parameter to take into consideration, and topical/local application of phyto-agents appears to be the most suitable in skin aging prevention and skin therapy (e.g. photoprotective and DNA-damaging repair effects) in particular because this route permits to reduce the efficacy dose and subsequently the overall systemic and organic toxicity [1$5,8]$. Interestingly, emulsions are frequently employed to establish new pharmaceutical and cosmetic formulations (e.g. creams) for either topical (e.g. skin applications), oral administration, or sometimes injection [10,11].

Emulsions (including macro-, micro- and nano-) are part of the colloids class, a two-phase systems of matter, in which the liquid of the dispersed phase (e.g. oil) is put in contact, albeit normally immiscible

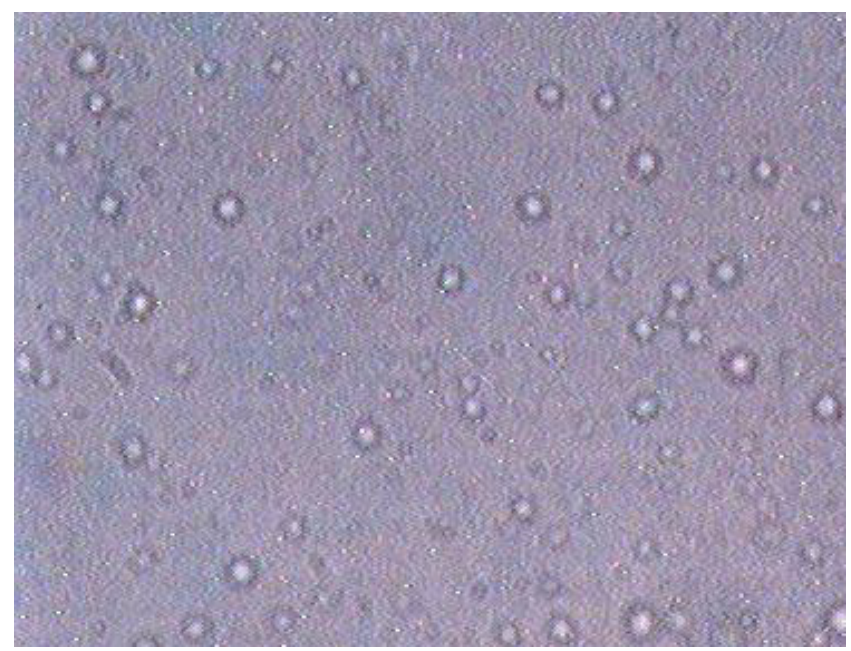

Figure 1: In house-made O/W macro-emulsion containing 5\% Cassia fistula L. [Caesalpinaceae (Fabaceae)] crude pod's extracts for skin anti-aging applications. (i.e. non-mixable or unblendable), with the liquid of the continuous phase (e.g. water) [9]. The droplets dispersed in the liquid matrix (aka "dispersion medium") are usually assumed to be statistically distributed (Figure 1).

Overall, there is emerging evidence that topical application of some emulsified plant extracts or pure phytochemicals can prettify the skin appearance and reduce a number of degenerative diseases as well as skin conditions such as skin inflammation, skin cancers and/or skin aging [12-15]. The ongoing challenge is to determine qualitatively and quantitatively, in the physiopathological context, which phytochemicals encapsulated into emulsions are really the most efficient and the safest.

\section{References}

1. Watson RR, Preedy VR, Zibadi S (2013) Polyphenols in Human Health and Disease (1st edn) Academic Press, Elsevier publisher, USA 63: pp819-829.

2. Watson RR, Preedy VR, Zibadi S (2013) Polyphenols in Human Health and Disease (1st edn) Academic Press, Elsevier publisher, USA 64: pp831-838.

3. Martirosyan DM (2013) Introduction to Functional Food Science (1st edn) Food Science Publisher 21: pp383-404.

4. Menaa F, Menaa A, Tréton J, Menaa B (2013) Dietary Intake of (-)-Epigallocatechin-3-gallate against Aging and Cancers: Nanoencapsulation of Multi- Rings Still Requires New Rounds!, J Nanomater Mol Nanotechnol 2: 7.

5. Menaa F, Badole SL, Menaa B, Menaa A (2013) Promising plant extracts with in vivo anti-melanoma potential (1st edn) Humana Press Inc, Springer, USA 26: $283-290$

6. Kora ARR, Khambholja KM (2011) Potential of herbs in skin protection from ultraviolet radiation. Pharmacogn Rev 5: 164-173.

7. Nichols JA, Katiyar SK (2010) Skin photoprotection by natural polyphenols: anti-inflammatory, antioxidant and DNA repair mechanisms. Arch Dermato Res 302: 71-83.

8. Menaa F, Menaa v, Menaa B (2013) Polyphenols nanoformulations for topical dermal delivery and skin tissue engineering $\left(1^{\text {st }}\right.$ edn $)$ Academic Press, Elsevier publisher, USA 65: 839-848.

9. Menaa F (2014) Emulsions Systems for Skin Care: From Macro to NanoFormulations. JPharma Care Health Sys 1: e104.

10. Aulton ME (2013)Aulton's Pharmaceutics: The Design and Manufacture of Medicines ( $3^{\text {rd }}$ edn) Taylor KMG, Churchill Livingstone, Elsevier: pp92-97.

11. Loyd VA, Remington JP, Beringer $P$ (2013) Remington: The Science and Practice of Pharmacy (21st edn) Philadelphia: Lippincott Williams and Wilkins 325-336.

12. Sharif A, Akhtar N, Khan MS, Menaa B, Khan BA, et al. (2014) Development and Optimization of Dimethicone-based Cream Containing Muscat Hamburg Grape Extract: In-vitro Evaluation. J Pharma Care Health Sys 1: 107.

*Corresponding author: Farid Menaa, Bionanomics Ltda, Sao Paulo, Fluorotronics, California, USA, E-mail: dr.fmenaa@gmail.com

Received November 07, 2014; Accepted November 08, 2014; Published November 10, 2014

Citation: Menaa F (2014) Skin Anti-Aging Benefits of Phytotherapeutics-based Emulsions. Pharm Anal Acta 5: e168. doi:10.4172/2153-2435.1000e168

Copyright: (c) 2014 Menaa F. This is an open-access article distributed under the terms of the Creative Commons Attribution License, which permits unrestricted use, distribution, and reproduction in any medium, provided the original author and source are credited. 
13. Khan BA, AkhtarN, Braga VA (2012)Anti-Aging Effects of Hippophaerhamnoides Emulsion on Human Skin. Trop J Pharm Res 11: 955-962.

14. Rasul A, Akhtar N, Khan BA, Mahmood T, UzZaman S, et al. (2012) Formulation development of a cream containing fennel extract: in vivo evaluation for antiaging effects. Pharmazie 67: 54-58.

15. Akhtar N, Mahmood T, Khan BA, Khan HMS, Saeed T (2011)Depigmenting and anti-erythematic effects of $3 \%$ green tea emulsion. HealthMED 5: 11651169. 